\title{
Immunological genomics of Brugia malayi: filarial genes implicated in immune evasion and protective immunity
}

\author{
RICK M.MAIZELS ${ }^{1}$, MARK L.BLAXTER ${ }^{1} \&$ ALAN L.SCOTT ${ }^{2}$ \\ ${ }^{1}$ Institute for Cell, Animal and Population Biology, University of Edinburgh, Edinburgh, UK and ${ }^{2}$ Department of Molecular Microbiology and \\ Immunology, Bloomberg School of Public Health, Johns Hopkins University, Baltimore, MD, USA
}

\section{SUMMARY}

Filarial nematodes are metazoan parasites with genome sizes of > 100 million base pairs, probably encoding 15 000-20 000 genes. Within this considerable gene complement, it seems likely that filariae have evolved a spectrum of immune evasion products which underpin their ability to live for many years within the human host. Moreover, no suitable vaccine currently exists for human filarial diseases, and few markers have yet been established for diagnostic use. In this review, we bring together biochemical and immunological data on prominent filarial proteins with the exciting new information provided by the Filarial Genome Project's expressed sequence tag (EST) database. In this discussion, we focus on those genes with the highest immunological profile, such as inhibitors of host enzymes, cytokine homologues and stage-specific surface proteins, as well as products associated with the mosquitoborne infective larva which offer the best opportunity for an anti-filarial vaccine. These gene products provide a fascinating glimpse of the molecular repertoire which helminth parasites have evolved to manipulate and evade the mammalian immune response.

Keywords filariasis, antigens, inhibitors, cytokine homologues, vaccine

Correspondence: Rick M.Maizels, Institute for Cell, Animal and Population Biology, University of Edinburgh, West Mains Road, Edinburgh EH9 3JT, UK (e-mail: rick.maizels@ed.ac.uk)

Received: 16 February 2001

Accepted for publication: 11 April 2001

\section{INTRODUCTION}

Filarial nematodes enjoy one of the longest lifespans of any human pathogen. Individual adult worms may live for 7 years or more (1), and their microfilarial offspring can remain in the bloodstream for at least 1 year (2). Their success implies highly effective immune evasion strategies (3). With immunological pathways becoming increasingly well defined, and with the progress of the filarial genome project (4), it is now possible to search for and characterize individual molecules from these parasites which encode proteins involved in neutralizing or evading the host immune response. These may also serve as ideal vaccine or drug targets.

One paradigm for immune evasion by pathogens has been provided by work on viruses $(5,6)$. Here, despite the constraints of small genome size $(<200 \mathrm{~kb})$ and limited gene number $(<200)$, there are a remarkable series of products which interfere with major histocompatibility complex (MHC) Class I antigen processing, or which mimic host cytokines or cytokine receptors. Nematode parasites may adopt similar strategems, with two interesting complexities. First, rather than capture immunomodulatory genes from their hosts, nematodes may use the genetic heritage they share with mammals, and adapt conserved regulatory molecules for immune evasion $(7,8)$. As nematode genomes are relatively large (100 million bp or more) and encode approximately 20000 proteins, the scope for expressing direct immune modulation products is immense. Second, nematode parasites such as the filariae can induce host cells to adopt a suppressive function (9), perhaps providing the longterm immunological tolerance thought to prevail in infection $(10,11)$.

Different approaches can be taken to identify immune evasion genes. The classical path has been to characterize major products found at the host-parasite interface, 
such as surface and secreted molecules, which led to the identification of antioxidant proteins on the filarial cuticle (12). Second, we can probe for predicted gene families by polymerase chain reaction (PCR), as used to isolate a homologue of transforming growth factor (TGF)- $\beta$ (13). With the database of expressed sequence tag (EST) sequences now exceeding 22,000, similar searches can be done in silico and, from this route, homologues of mammalian macrophage migration inhibitory factor (MIF) have been discovered $(7,14)$. Third, we can use abundance alone as a measure of importance leading us to discover novel genes with no precedent in other infectious organisms $(15,16)$. The completion of the Caenorhabditis elegans genome (17) adds a comparative dimension to these studies because immune evasion genes would be expected to have diverged sharply from homologues expressed in C. elegans or even represent proteins altogether absent from the freeliving organism.

The rate of gene discovery in large parasite genomes is rapidly accelerating, due to the success of EST projects which perform large-scale sequencing of cDNAs from multiple life cycle stages (18). For example, it is estimated that approximately one-third of the predicted 20000 genes in the filarial nematode Brugia malayi are represented in at least one EST sequence $(4,19)$. It is essential that stock is taken regularly of the advances offered by genome-based research, and that new information is effectively integrated with both existing and new protein-based analyses. The purpose of this review is to summarize the most prominent and promising filarial gene products in the realm of immunology, focusing on those proteins most likely to play a role in immune evasion and modulation on behalf of the parasite, and/or most implicated as targets of the immune response including those with potential for new vaccines.

Filarial nematodes belong to the family Onchocercidae (Table 1). Of several human pathogens, only $B$. malayi can be readily maintained in laboratory animals, and this species has consequently been studied in greatest detail. Where comparisons can be made between homologous genes from different species, high levels of sequence conservation are generally seen $(13,20,21)$. It is valuable therefore to integrate all available information from related species to establish the function of novel proteins from these parasites.

Table 2 lists a selection of $B$. malayi genes for which full cDNA sequence is available and which are implicated as important components that influence the host immunological profile. Together with essential information on each protein, we have also conducted a virtual expression profile (4), enumerating the frequency with which each transcript is represented in EST sequences derived from each stage of the life cycle. Thus, both stage-specific and constitutive genes can be identified, and particular features from this analysis are referred to under the respective gene below. Table 3 summarizes the similarities of

Table 1 Gene and protein sequences from filarial nematodes in public databases (as of 8 January 2001)

\begin{tabular}{|c|c|c|c|c|}
\hline & Nucleotide sequences & Protein sequences & Protein structures & ESTs \\
\hline \multicolumn{5}{|l|}{ Human pathogens } \\
\hline Brugia malayi & 517 & 153 & 3 & 22392 \\
\hline Onchocerca volvulus & 581 & 256 & 0 & 13806 \\
\hline Wuchereria bancrofti & 35 & 30 & 0 & 131 \\
\hline \multicolumn{5}{|l|}{ Animal models } \\
\hline Acanthocheilonema viteae (jird) & 18 & 23 & 0 & 0 \\
\hline Brugia pahangi (jird/cat) & 57 & 79 & 0 & 28 \\
\hline Dirofilaria immitis $(\mathrm{dog})$ & 61 & 64 & 0 & 0 \\
\hline Litomosoides sigmodontis (mouse) & 14 & 15 & 0 & 198 \\
\hline Onchocerca ochengi (cow) & 6 & 5 & 0 & 60 \\
\hline \multicolumn{5}{|l|}{ Other human parasites } \\
\hline Brugia timori & 1 & 0 & 0 & 0 \\
\hline Loa loa & 8 & 5 & 0 & 0 \\
\hline Mansonella perstans & 1 & 0 & 0 & 0 \\
\hline $\begin{array}{l}\text { Total } \\
\text { (including additional minor datasets) }\end{array}$ & 1329 & 641 & 3 & 36615 \\
\hline
\end{tabular}


homologues from other filarial species, and from $C$. elegans, where these are known. The main part of this review discusses the categories of filarial proteins thought to be important in the immunological interaction between host and parasite. These genes are summarized in Table 2.

\section{ADULT SURFACE-ASSOCIATED PROTEINS.}

\section{Gp29 or Bm-GPX-1 (glutathione peroxidase)}

The major surface-associated proteins of adult $B$. malayi have been identified by molecular cloning. The dominant noncollagenous component is a $29 \mathrm{kDa}$ glycoprotein designated gp29 (22) and subsequently identified as a glutathione peroxidase, $B m$-GPX-1 (12). This enzyme has activity against lipid peroxides in preference to hydroperoxide (23), and thus may protect the lipid phase of the epicuticle from immune reactive-oxygen intermediate attack. It may also have a role in modifying or removing host immunomodulatory lipids (24). Thus, Bm-GPX-1 was the first filarial product for which an explicit role was proposed in defending parasites against host immunity. However, there is no evidence as yet that host responses against $B m$-GPX-1 can protect against infection because antibodies to this protein are present in most infected individuals.

Bp-GPX-1 from Brugia pahangi shows an identical amino acid sequence (25) while that from Wuchereria bancrofti diverges by only 3\% (20) (Table 3). However, there are a number of synonomous nucleotide substitutions, with introns diverging by $10 \%$ (B. malayi/B. pahangi) and $28 \%$ (Brugia/Wuchereria). Curiously, no homologue has been found in Onchocerca parasites. A three-dimensional model is available in which the Brugia GPX-1 structure has been predicted according to the bovine homologue (26). The residues differing between the filarial genera map to the exterior of this model, consistent with either neutral drift of structurally unconstrained amino acids, or variation at antigenically significant positions.

\section{Gp15/400 or NPA-1 (nematode polyprotein allergen)}

Among the most intriguing components of the adult nematode surface is gp15/400, a repeat-motif protein with variable numbers of $15-\mathrm{kDa}$ subunits, giving a molecular weight range from $15 \mathrm{kDa}$ to approximately $400 \mathrm{kDa}(22,27)$. This polyprotein is related to antigens from many different nematodes, including the Ascaris body fluid allergen ABA-1 (28-30). The gene family has thus been designated npa (nematode polyprotein allergen/antigen) (31). Bm-NPA-1 is synthesized as a $400 \mathrm{kDa}$ precursor, containing regularly spaced 132-amino acid subunits separated by tetrabasic motifs. Incomplete cleavage of the primary translation product at these tetrabasic sites is thought to yield the characteristic 'ladder' observed on SDS-PAGE gels $(28,32)$. All known nematode genes for NPA proteins contain 10 or more degenerate tandem repeats, although the degree to which sibling repeats vary within a single gene differs greatly according to species (21).

$B m$-NPA-1 is secreted by adult parasites $(28,29)$, and is a major target for immunoglobulin (Ig)E antibody responses (33), indicating a prominent immunogenicity in vivo. Filarial and other nematode NPA bind retinol and fatty acids with high affinity. NPA-1 could be considered to act as a 'worm albumin', perhaps sequestering host signalling lipids (34). The Dirofilaria immitis protein has also been reported to act as a neutrophil chemotactic factor (35), indicating some form of recognition by the innate immune system of a protein which may perhaps be essential for worm survival in the host.

\section{Bm15 or Bm-CPI-2 (cysteine protease inhibitor-2)}

Second in prominence to gp29 on the surface of adult Brugia is a $15 \mathrm{kDa}$ nonglycosylated surface protein, Bm15 (36,37). This protein is also evident in parasite secretions (37), and is present on the L3 surface. Once cloned, its sequence revealed similarity to vertebrate cysteine protease inhibitors or cystatins, and it has been designated $B m$-CPI-2 (cysteine protease inhibitor-2), in distinction to the L3-specific cystatin Bm-CPI-1 described below (38). Close homologues of $\mathrm{Bm}$-CPI-2 have been reported from Onchocerca volvulus $(39,40)$ and Acanthocheilonema viteae (41), and the latter molecule directly inhibits $\mathrm{T}$ cell proliferation and induces interleukin (IL)-10 release from murine macrophages (41).

The CPI-2 homologues from these three species contain an intriguing 23-amino acid $\mathrm{N}$-terminal extension absent from all other members of the family. This flanking sequence has been suggested to fulfil another function, such as targetting for entry into host cells. If so, $B m$-CPI-2 would be a novel example in the evolution of cystatins. A further point of interest is that EST sequences for Bm-cpi-2 so far deposited reveal approximately equal numbers of two variants differing by a single amino acid (Asn or Lys at residue 90). Such 
Table 2 B. malayi genes for which full cDNA sequence is available

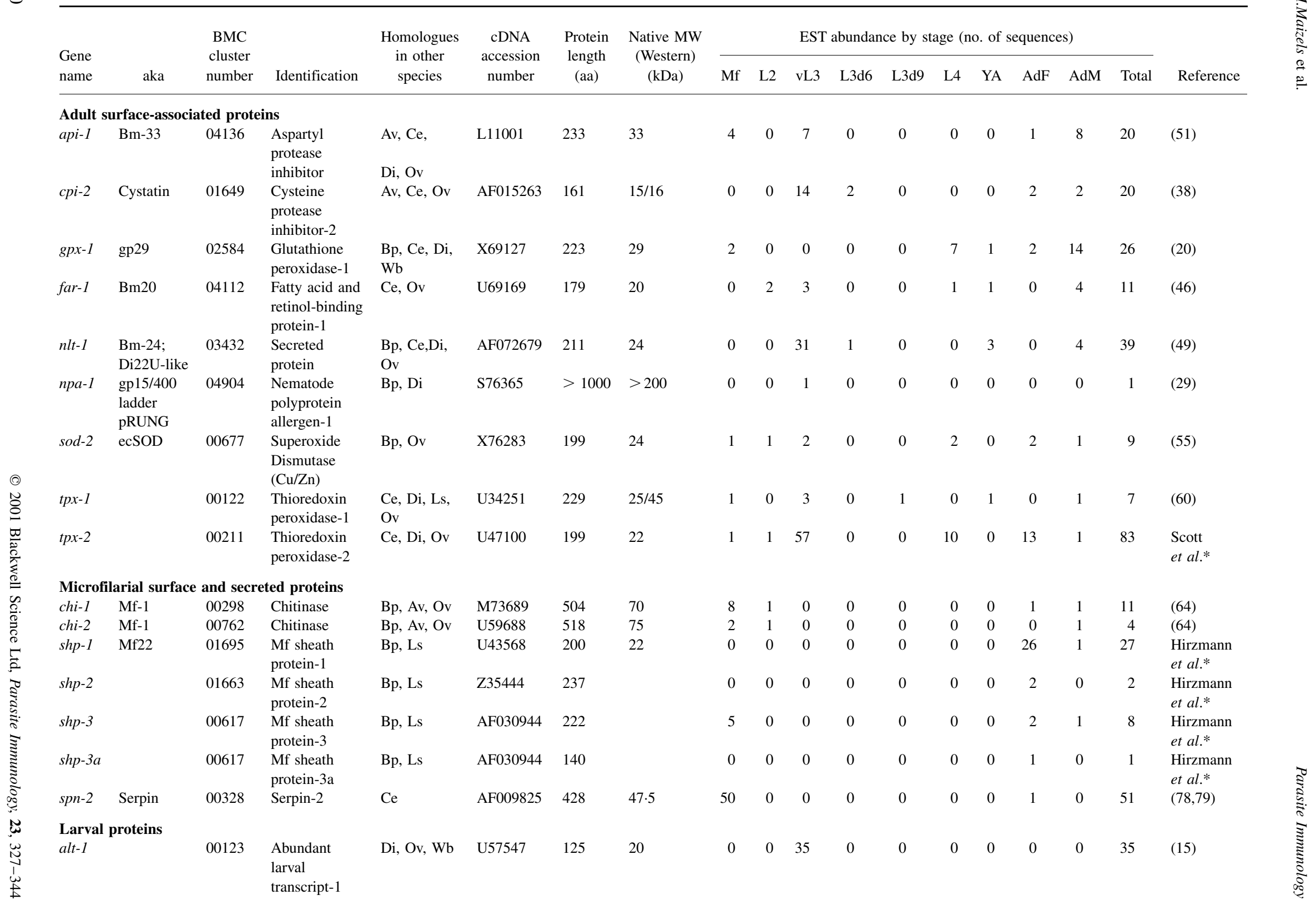




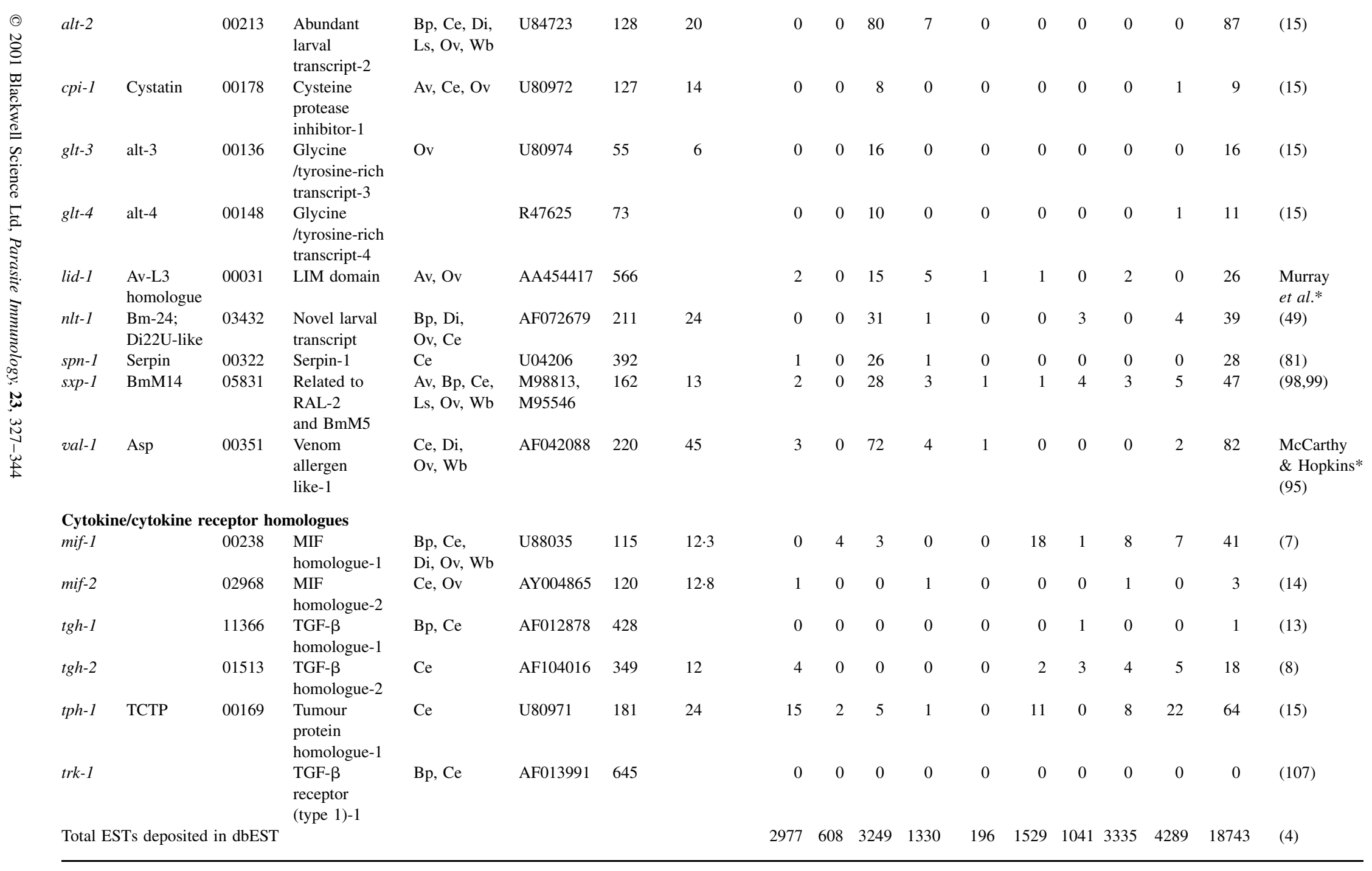

*Unpublished data. 
Table 3 Amino acid identities between key filarial proteins from different species

\begin{tabular}{|c|c|c|c|c|c|c|c|c|c|c|}
\hline \multicolumn{2}{|c|}{ B. malayi } & \multirow{2}{*}{$\begin{array}{c}\text { Length } \\
\text { (amino acids) }\end{array}$} & \multirow[b]{2}{*}{ B. pahangi } & \multirow[b]{2}{*}{ W. bancrofti } & \multirow[b]{2}{*}{ L. sigmodontis } & \multirow[b]{2}{*}{ A. viteae } & \multirow[b]{2}{*}{ D. immitis } & \multirow[b]{2}{*}{ O. volvulus } & \multirow{2}{*}{\multicolumn{2}{|c|}{$\begin{array}{c}\text { C. elegans } \\
\text { Presumed orthologue }\end{array}$}} \\
\hline Gene & Protein & & & & & & & & & \\
\hline alt -2 & ALT-2 & 128 & $96.9 \%$ & $87.0 \%$ & $64.8 \%$ & $64.8 \%$ & $57.8 \%$ & $46.6 \%$ & $19.0 \%$ & CO8A9 \\
\hline api-1 & API-1 & 233 & & & & $76 \cdot 1 \%$ & $75 \cdot 2 \%$ & $72 \cdot 2 \%$ & $41.5 \%$ & F35A5.4 \\
\hline cpi-2 & CPI-2 & 161 & & & & $66 \cdot 0 \%$ & & $65.0 \%$ & $26 \cdot 7 \%$ & $\mathrm{R} 01 \mathrm{~B} 10 \cdot 1$ \\
\hline far -1 & FAR-1 & 178 & & & & & & $83.8 \%$ & $34 \cdot 1 \%$ & F02A9·2 \\
\hline$g p x-1$ & GPX-1 & 223 & $100.0 \%$ & $96.9 \%$ & & & $74.0 \%$ & & $52.9 \%$ & $\mathrm{C} 11 \mathrm{E} 4 \cdot 1$ \\
\hline mif-1 & MIF-1 & 115 & $86.0 \%$ & $93.0 \%$ & & & $84.0 \%$ & $85.0 \%$ & $35 \cdot 0 \%$ & Y53A3A.3 \\
\hline mif-2 & MIF-2 & 115 & & & & & & $75.0 \%$ & $38.0 \%$ & $\mathrm{C} 52 \mathrm{E} 4 \cdot 2$ \\
\hline $\operatorname{shp}-1$ & SHP-1 & 200 & $90 \cdot 0 \%$ & & $45.8 \%$ & & & & & \\
\hline sxp-1 & SXP-1 & 153 & $30 \cdot 0 \%$ & $82.5 \%$ & $43.0 \%$ & $32.0 \%$ & & $58.9 \%$ & $27.2 \%$ & F57H12.2 \\
\hline $\operatorname{tgh}-1$ & TGH-1 & 428 & $99.1 \%$ & & & & & & $42 \cdot 4 \%$ & $d b l-1$ (T25F10) \\
\hline$t p x-1$ & TPX-1 & 229 & $49.0 \%$ & & $63.0 \%$ & & $60 \cdot 0 \%$ & $62.0 \%$ & $65.0 \%$ & R07E5.2 \\
\hline val-1 & VAL-1 & 220 & & $90.9 \%$ & & & $63 \cdot 3 \%$ & $55.0 \%$ & $17 \cdot 8 \%$ & T05A10.4 \\
\hline
\end{tabular}

Percentage identities are calculated as exact matches between the B. malayi deduced protein sequence and that of the closest known homologue from other filarial species. It is possible that some comparisons are not between true orthologues. Slightly different calculations can be reached depending on the numbers of gaps permitted in alignments.

evidence for coding polymorphisms remains rare among filarial proteins.

The functions of $\mathrm{Bm}$-CPI-2 present an instructive example of how filarial proteins may interfere with the host immune response. Sequence analysis reveals two potential active sites, the universal papain-inhibiting motif common to $\mathrm{Bm}$ CPI-1 and -2, and a second SND-containing site, found in $B m$-CPI-2, which blocks enzymes of the legumain or asparaginyl endopeptidase (AEP) clade (42). Interestingly, an AEP is involved in the MHC class II antigen processing pathway (43), and recent work has established that purified recombinant $\mathrm{Bm}$-CPI-2 can specifically inhibit AEP activity and block the class II-dependent presentation of exogenous antigen by human B cells (44).

\section{Bm20 or Bm-FAR-1 (fatty acid and retinol binding protein)}

Surface labelling of adult B.malayi gives weaker and variable iodination of a $20 \mathrm{kDa}$ protein related to Ov20, a much more prominent surface antigen on adult $O$. volvulus (45). Including the conserved signal sequence, both $\mathrm{Bm}$ FAR-1 and Ov20, are 178 amino acids in length, but the proteins differ in 26/160 amino acids (84\% identity) over the mature polypeptide (46). Three of these substitutions replace asparagine residues found in Ov20, nullifying potential glycosylation sites, and although one new site is observed in Bm-FAR-1, this is thought not be used in the native product.

While Ov20 is recognized by serum antibodies from a high proportion of onchocerciasis patients (47), the B. malayi homologue has a lower immunological profile, and only marginal serological responses are detected in lymphatic filariasis patients (46). However, both Onchocerca (48) and Brugia (Allen \& Kennedy, personal communication) proteins show functional fatty acid and retinol binding, and the gene has accordingly been re-designated far-1. Because no NPA-1 homologue has yet been found in $O$. volvulus, it may be that Ov20 is upregulated to provide a compensatory level of retinol binding in the Onchocerca species.

\section{Bm-24 or Bm-NLT-1 (novel larval transcript; D. immitis-P22U-like)}

In D.immitis, a secreted $22 \mathrm{kDa}$ protein (Di-P22U) has been isolated, antibodies to which react with a $24 \mathrm{kDa}$ surface-labelled protein from the L3 and L4 of $B$. malayi; the same antigen is also weakly represented on the adult parasite (49). Electron microscopy locates Di$\mathrm{P} 22 \mathrm{U}$ to the cuticle and hypodermis of adult $D$. immitis, but the protein is evidently obscured on the surface because no binding is detected by immunofluorescence assays on intact worms. Cloning of the $B$. malayi homologue reveals a 211-amino acid protein 
with a typical signal peptide (49). This sequence matches a highly expressed vector-derived L3 transcript in the B. malayi EST database which has been designated Bm-nlt-1 or novel larval transcript-1 (50). So far, no insight has been gained into the biological function of this product, and there are as yet no data on immunological recognition by infected or immune hosts.

\section{Bm33 or Bm-API-1 (aspartyl protease inhibitor)}

A minor protein observed by surface labelling adult B. malayi is $\mathrm{Bm}-33$, a $33 \mathrm{kDa}$ protein with similarity to the aspartyl protease inhibitor gene family (51). The best characterized homologue is in $O$. volvulus, in which the immunodominant Ov-33 antigen elicits strong antibody responses in $96 \%$ of patients (52); similarly, a high proportion of $B$. malayi-infected patients express antibodies to Bm-API-1, particularly of IgG1 and IgG4 isotypes (16). Functionally, Ov-33 expressed in yeast shows inhibition of the aspartyl protease pepsin (53), and the presence of a 17-amino acid putative signal peptide at the $\mathrm{N}$-terminus of $\mathrm{Ov}-33$ and $\mathrm{Bm}-33$ indicates that the product may be secreted by the filariae. Filarial aspartyl protease inhibitors show between $20 \%$ and $25 \%$ sequence identities to known inhibitors from nonfilarial nematodes, such as Ascaris PI-3 (51) which have been shown to interfere with a murine cathepsin $\mathrm{E}$ involved in antigen processing (54). No immunological role for the filarial aspartyl protease inhibitors has yet been established, although it is plausible that a similar set of host aspartyl proteases are physiological target of these inhibitors.

\section{Bm-SODs (superoxide dismutases)}

Biochemical analysis of the antioxyradical defences of B. malayi indicated the presence of superoxide dismutase, a key enzyme in detoxification of reactive oxygen intermediates produced by host granulocytes. Two distinct Brugia SOD genes have been cloned (55). One encodes an intracellular (cytoplasmic) SOD, while the second is a secreted extracellular isoform. The secreted SOD is found at the surface of adult nematodes, and is identified as a low abundance $22 \mathrm{kDa}$ product accessible to iodine labelling (56). Together with GPX, SOD probably provides the parasite with essential defence against reactive oxygen species. Notably, adult Brugia are relatively resistant to killing by superoxide compared to the microfilariae, which do not express either GPX-1, nor the SOD genes (57).

(C) 2001 Blackwell Science Ltd, Parasite Immunology, 23, 327-344

\section{Bm-TPXs (thioredoxin peroxidases)}

Thioredoxin peroxidases (TPXs) are a large family of antioxidant proteins produced by organisms from all kingdoms. The members of the TPX family have various assignations such as thiol-specific antioxidants (TSA) (58), peroxidoxins (PXN) (59), and natural killer cell enhancing factor (NKEFA) (59). The antioxidant activity of TPX is based on its ability to efficiently degrade $\mathrm{H}_{2} \mathrm{O}_{2}$ and alkyl hydroperoxides, thus preventing the production of toxic hydroxyl radicals that damage proteins, lipids and DNA (59).

The Brugia EST database has revealed that, similar to a majority of eukaryotic organisms, Brugia transcribes two distinct classes of tpx genes. One class includes both $B m$-TPX-1 (25 kDa) and Bm-TPX-2 $(22 \mathrm{kDa})$. Although only $55 \%$ identical in amino acid sequence, both proteins contain two highly conserved cysteine residues that correspond to Cys-47 and Cys170 of the prototype TPX from yeast (58). The second class of tpx gene encodes $B m$-TPX-3 (26 kDa) which is approximately $20 \%$ identical in amino acid sequence to $B m$-TPX-1 and Bm-TPX-2 and lacks the conserved Cys-170. While it has been demonstrated that a recombinant form of $\mathrm{Bm}$-TPX-1 is capable of protecting DNA from oxygen-radical-induced damage (60), BmTPX-2 and Bm-TPX-3 have not been tested for biological activity. However, the orthologues of $B m$-TPX-2 and Bm-TPX-3 from $O$. volvulus have been shown to have antioxidant activity $(61,62) . B m-$ tpx1 and Bm-tpx-2 have similar patterns of expression with peaks of transcription in the vector-stage L3s and in adult females (Table 2). Bm-tpx-3 appears to have a much lower level of transcription with 3,2 and 1 ESTs from the microfilarial, male and female libraries, respectively (data not shown).

The roles that the Brugia-derived TPXs play in the immunobiology of infection have not been fully defined. Bm-TPX-1, which is not secreted, contains a mitochondrial localization signal. Presumably, this TPX functions to protect cells from the endogenously produced toxic byproducts of aerobic metabolism (60). Studies to define the localization and function of Bm-TPX-2 and Bm-TPX-3 have not been carried out. However, $O v-\mathrm{TPX}-2$ is associated with the surface of microfilariae where it may serve to protect the parasite from host-derived oxidative damage (62).

\section{MICROFILARIAL SURFACE AND SECRETED ANTIGENS}

Microfilariae (mf) of lymphatic filarial nematodes (Brugia, 
Wuchereria) and certain other species (e.g. Litomosoides sigmodontis) are enveloped in a sheath, separate from the cuticle, which is derived from the eggshell in utero. The $\mathrm{mf}$ are thought to retain their sheath within the mammalian host, and to exsheath in the vector blood meal. Strictly, surface antigens of the $\mathrm{mf}$ relate to the sheath components, but surface-iodination reagents penetrate the sheath and label cuticle proteins, some of which are also described below.

\section{Chitinases, MF-1, Bm-CHI-1/2}

Surface iodination of $B$. pahangi mf labels a triplet of proteins of approximately $70 \mathrm{kDa}$ (36), while an mfreactive monoclonal antibody, MF-1, binds two bands of this size in B. malayi $\mathrm{mf}$ (63). The smaller of the $B$. malayi proteins, p70, was cloned first (64), and proved to be a functional chitin-degrading enzyme with a preference for internal cleavage of chitin polymers. $\mathrm{N}$ terminal sequencing confirms that both p70 and the larger p75 from B.malayi, and all three isoforms (p69, p73, p76) in B. pahangi are closely related (65). The structure of p70 (Bm-CHI-1) reveals a large catalytic domain with close homology to eukaryotic and bacterial chitinases, a mucin-like domain with three 14-amino acid repeats rich in serine, threonine and acidic residues, and a $C$-terminal 57-amino acid 6-cysteine domain. Southern blot analysis later indicated that there are at least two chitinase genes in B. malayi (66). A larger transcript, containing an additional 14-amino acid repeat in the serine/threonine-rich tract, was then isolated which may encode p75 (65).

The catalytic domain is the only one with homology to chitinases from bacteria, yeast and other metazoa. However, many other chitinases include adjacent mucinlike and cysteine-rich domains. For example, insect chitinases contain $C$-terminal regions with six cysteine residues which align closely to the Brugia sequence. This arrangement, termed $\mathrm{NC} 6 / 2$, is also found in other nematodes including $C$. elegans (67). Cysteine-rich domains from other chitinases function to recruit and/or hold chitin substrate to maximize activity (68). Such a role is supported by findings that chitin binding by recombinant $B m$-CHI-1 is diminished when the $C$ terminal noncatalytic segments are removed from the protein (69).

The expression of $\mathrm{Bm}$-CHI-1/2 shows an interesting pattern. It is absent from adult worms and newborn mf, but synthesis is initiated from 2 days after birth, and reaches a plateau 2 weeks later $(63,70)$. Because 'immature' $\mathrm{mf}$ are known to be incompetent at infection of mosquitoes (63), the chitinases may play their role in effecting transmission through the vector. Three possible mechanisms have been suggested (70): degradation of the $\mathrm{mf}$ sheath, a chitin-rich structure from which mf must escape in the blood meal; breakdown of a chitin-containing barrier such as the peritrophic membrane in the mosquito vector; or enzymatic release of chitobiose sugars in the mosquito, blocking vector agglutinins from attacking the parasite. As yet, none of these alternatives can be excluded.

An immunological role for chitinases in the mammalian host may also be important. Although in Brugia, chitinase expression is mf-specific, the homologous protein is prominent in $A$. viteae infective larvae $(71,72)$. Av-CHI-1 is strongly recognized by serum antibodies from jirds vaccinated with irradiated L3 of this species, and is not even expressed by $\mathrm{mf}$ (71). Moreover, a homologue is also expressed in L3 of $O$. volvulus, a species in which $\mathrm{mf}$ do not carry a sheath (72).

The filarial chitinases are only distantly related to a $43 \mathrm{kDa}$ chitinase reported to be recognized by humans immune to W. bancrofti infection (73); subsequent cloning (74) revealed a sequence most similar to the Rickettsial organism Serratia, indicating that the L3-chitinase in W. bancrofti is encoded by the endosymbiotic Wolbachia (see below). It is interesting to consider that chitinase expression may be essential for filarial L3 stages, but that in $W$. bancrofti this requirement is fulfilled by the endosymbiotic bacteria rather than by a filarial-derived gene.

\section{Major sheath proteins: $B m-S H P-1$ or Mf-22 and Bm-SHP-2}

Following the identification of a major sheath protein, Mf22, by Selkirk et al. (75), the Giessen group performed a comprehensive analysis of filarial sheath proteins, renaming Mf22 as SHP-1. Using L. sigmodontis as their model, four further SHP proteins have been defined (76). One of these additional products (Bm-SHP-2) has been fully characterized from $B$. malayi (77), and SHP-3 homologues are present in the EST database. In general, the mRNAs for these products are expressed only in the female uterus.

One striking feature of SHP-1 is the extent of diversity between the two Brugia species. While GPX-1 shows a complete identity of amino acid sequence between these two species (Table 3), Bm- and Bp-SHP-1 display over 10\% variation in amino acid sequence, including two indels (Bp-SHP-1 has a GGA insertion at nt 79-81, the ATG codon being 1-3; there follows a 42-nt tract almost identical between the two species, and then a GGA 
insertion only in $\mathrm{Bm}$-SHP-1. Thus the two sequences are of identical length). Remarkably, analysis of the EST data indicate that some of the $B$. malayi entries possess the $B$. pahangi indel pattern. Although it is conceivable that these represent two distinct genes, it remains an attractive possibility that MF-22 displays a degree of polymorphism or variation.

Bm-SHP-2 is a 236-amino acid protein containing both proline-alanine tracts and a segment rich in glutamines and tyrosines, the latter being suitable substrates for cuticlin-like oxidative cross-linking (76). In L. sigmodontis, three further sheath proteins have been identified (SHP-3, -4 and -5), including components exposed on the outermost layer of the $\mathrm{mf}$ sheath (76). Homologues for SHP-4 and -5 have yet to be found in B. malayi.

\section{Serpin: serine protease inhibitors (Bm-SPN-1 and -2)}

The most abundant microfilarial-specific transcript from B. malayi encodes a serine protease inhibitor (serpin), a 428 -amino acid $47.5 \mathrm{kDa}$ protein found only in this stage of the parasite. $B m-\mathrm{SPN}-2$ is homologous to mammalian protease inhibitors such as $\alpha$-1-antitrypsin, but has no inhibitory activity against common serine proteases such as trypsin, pancreatic elastase, or the thrombin-cleaving enzymes (78). However, $B m-\mathrm{SPN}-2$ is able to inhibit the activity of neutrophil elastase and cathepsin G, two major proteases secreted by the most abundant cell type in the blood, the habitat of the microfilaria itself.

$B m-S P N-2$ is the only antigen so far to have been selected on the basis of strong stimulation of host $\mathrm{T}$ cells (79), in distinction to others isolated by antibody reactivity or mRNA abundance. Moreover, $\mathrm{Bm}-\mathrm{SPN}-2$ drives a response rarely seen in helminth infections, dominated by a type 1 (Th1) phenotype. It is known that live $\mathrm{mf}$ induce a relatively strong Th1-type response in mice, in contrast to the adult and larval stages which drive overwhelmingly Th2-like reactions (80). Bm-SPN-2 is able to recall pure Th1 responses in mf-primed cells, whereas even mf extract develops a balanced response with both subsets represented (79). The molecular basis for the Th1-bias in Bm-SPN-2 remains to be investigated.

In contrast, $B m$-SPN-1 is expressed at a high level in mosquito-derived larave, but minimally by any stages in the mammalian host (81). Moreover, at a sequence level, BmSPN-1 represents a very distinct branch of the family not closely related to $\mathrm{Bm}$-SPN-2 (82).

\section{THIRD STAGE LARVAL ANTIGENS}

Although surface-labelling data exist for Brugia infective larvae $(36,83)$, the surface antigens from this stage have not been fully identified. Both cystatin proteins (Bm-CPI-1 and CPI-2) can be iodinated by surface-directed methods, and are secreted by L3 maintained in vitro, while Bm-24 can also be identified in surface-iodinated L3 preparations (49). A molecular approach to identify major L3 proteins by mRNA or EST abundance indicates which proteins may be required in quantity for invading parasites. Most highly expressed overall are genes for Bm-ALT-2, BmVAL-1 and Bm-ALT-1 (50); and among other prominent transcripts are Bm-nlt-1,Bm-tpx-2, Bm-cpi-1 and Bm-spn1. Of these only Bm-alt-1/-2, Bm-cpi-1 and Bm-spn-1 are trans-spliced with the conserved nematode 22-nt leader sequence $(15,81)$.

\section{Bm-CPI-1 (cysteine protease inhibitor-1)}

The first cysteine protease inhibitor to be identified in Brugia was isolated from an analysis of highly expressed trans-spliced mRNAs from the L3 stage (15). Bm-cpi-1 expression, as revealed by a fine analysis with mRNA taken at daily intervals throughout the life cycle, is initiated in late L2 and L3 in the mosquito vector, but terminates within 2 days of infection of the mammalian host. In contrast, Bm-cpi-2 is constitutively expressed at all stages of the parasite life cycle. BmCPI-1 can be surface-labelled on the mosquito L3 and is found in secretions. $\mathrm{Bm}$-CPI-1 (similar to $\mathrm{Bm}$-CPI-2) is a good inhibitor of papain and cathepsin B, but the physiological target of this product (whether in mosquito, mammal or within the nematode itself) has yet to be defined.

\section{Abundant larval transcripts (Bm-alt-1, -2)}

In a strategy to identify parasite gene products required for invasion and establishment in the mammalian host, we set out to characterize those mRNAs from $B$. malayi L3 which are highly expressed in mosquitoborne infective larvae (15). The $5^{\prime}$ spliced leader sequence found on a proportion of nematode mRNAs (84) was combined with an oligo-dT primer to PCR amplify all trans-spliced transcripts $(81,85)$. Two highly expressed genes were designated alt (abundant larval transcript) -1 and -2 (15). The corresponding proteins are closely related (79\% amino acid identity) small proteins of 125-128 amino acids. An acidic tract near the $\mathrm{N}$-terminus contains most of the variation between the two polypeptide sequences. Significantly, 
alt mRNA expression is essentially limited to the larval stages, and is not detectable in Mf or adult worms (16).

The Filarial Genome Project provides an independent assessment of the abundance of these two products $(18,19)$. alt- 2 represents $>3 \%$ of all L3 ESTs, and alt-1 approximately $1.5 \%$ (50). The ALT- $1 /-2$ proteins are stored in the oesophageal gland of B. malayi L3 (Wu et al., personal communication), and are secreted by larvae when cultured following recovery from mosquitoes (Murray and Maizels, unpublished data). Such prominent expression implies a critical role in parasite entry into the host. We therefore tested Bm-ALT-1 for its ability to vaccinate jirds (Meriones unguiculatus) against B. malayi L3 challenge. Immunization resulted in a $76 \%$ reduction in worm load, the highest yet reported for a recombinant filarial antigen (16).

The alt gene family is also conspicuous in other filarial nematode species (50). In D. immitis, the Di20/22L protein is found in the L3 ES and is strongly recognized by sera from immune dogs (86). In $O$. volvulus, alt transcripts comprise $4.6 \%$ of L3 mRNA, anti-ALT-1 antibodies stain the glandular oesophagus, and Ov-ALT elicits partial protection in mice (87). alt-1 also ranks highest in abundance among transcripts from L3 of L. sigmodontis (50), and an A. viteae homologue (Av18) figures strongly in material released by moulting L3s (88). The Brugia EST dataset includes a number of other ALT-related gene transcripts suggesting that the gene family may be significantly larger in some filaria (Gregory et al., unpublished). Thus, across the range of species, ALT proteins are important candidates for a specific vaccine against filarial infection (16).

\section{Glycine-tyrosine rich abundant transcripts (Bm-glt-3, -4)}

Additional highly expressed trans-spliced transcripts from L3 are two genes originally assigned Bm-alt-3 and -4 (15). Because their sequence is not related to the alt-1/-2 family, these genes have been redesignated Bm-glt-3 and -4 . Detailed expression profiling of $\mathrm{Bm}$-glt-3 around the filarial life cycle shows it to be initiated midway through the mosquito phase, during L2, and terminated immediately following infection; there is no expression by mature mammalian stages (Gregory and Maizels, unpublished data). Similar to the ALT proteins, there is no indication of the functions of the putative GLT proteins. However, 11 homologous genes exist in C. elegans, in two arrays each containing five copies, plus a single additional copy, all on chromosome 5 (Gregory, unpublished data). This evidence for gene multiplication implies an important functional role, possibly conserved between free-living and filarial nematodes.

\section{Bm-LID-1 (Ov-L3 homologue)}

An interesting antigen was isolated from the L3 of $O$. volvulus by screening a cDNA library with serum from a human volunteer vaccinated with irradiated L3 larvae (89). This clone, initially termed Ov-L3-1, encodes a protein with a LIM domain, a motif identified in a variety of vertebrate genes, including those encoding certain adhesion proteins and transcription factors. The full-length Brugia homologue, Bm-LID-1, contains 588 amino acids with six potential $N$-linked glycosylation sites and multiple CxxC motifs (Murray \& Maizels, unpublished data). There is no typical signal sequence and, in $O$. volvulus at least, the mature protein is relatively insoluble, arguing that LID1 is not a secreted protein. However, Bm-lid-1 is relatively highly transcribed by $B$. malayi L3, and this elevated expression may account for the strength of the immune response.

\section{Venom allergen-like protein, $\mathrm{Bm}$-VAL-1 (also known as Ancylostoma secreted protein homologue)}

A prominent transcript among ESTs from B. malayi L3 (18) is a member of an expanding gene family for which the prototype is Ancylostoma secreted protein (ASP), first identified in the hookworm Ancylostoma caninum (90). The Ancylostoma ASP is a front-running vaccine candidate against canine hookworm. Subsequently, related genes have been identified in a range of other nematode species, including products which block neutrophil activation (91) and induce angiogenesis in mice (92).

Members of this family have either single (approximately 200 amino acids) or double (approximately 400 amino acids) homology units, preceded by signal sequences. In $C$. elegans there are at least 20 homologous genes, only one of which has a double-domain structure $(93,94)$. Because the asp gene name in $C$. elegans is assigned to an aspartic protease, the filarial gene is designated Bm-val-1.

The full sequence of the ASP-like B. malayi homologue contains a single consensus domain (95). Bm-val-1 transcripts are the second most-abundant among ESTs from the vector-borne L3 stage, but are poorly represented in cDNA libraries from other points in the life cycle (50). However, a finer analysis using first-strand cDNA taken at daily intervals revealed intermittent expression by mature mammalian stages, including adult parasites (95), so that Bm-val-1 is not stringently stage-specific in its expression. Perhaps reflecting this, human antibody responses to 
Bm-VAL-1 noted in most infected patients include a substantial IgG4 component in addition to IgG1 and IgG3 (95).

\section{Bm-SXP-1}

$\mathrm{Bm}$-SXP-1 (the gene name is not an acronym) is not larvalspecific as it was first isolated as an immunodominant clone from a male cDNA library. SXP-1 was subsequently shown to be useful as a serodiagnostic reagent for patients with patent infections with lymphatic filariasis, including infections with $W$. bancrofti $(96,97)$. Bm-SXP-1 is a member of a nematode-specific family of proteins that are $12-14 \mathrm{kDa}$ in mass and are distinguished by a highly conserved motif structure (98). There is a high level of serological reactivity to Bm-SXP-1 by lymphatic filariasis patients (99), predominantly of the IgG4 isotype, and a percentage of patients with patent $O$. volvulus and Loa loa infections also recognize Bm-SXP$1(96,97)$. Based on the utility of $B m$-SXP-1 to diagnose patent infections, it would be predicted that the expression profile would show enhanced transcription at the microfilarial stage. The EST database suggests that, while it is transcribed by all of the stages present in the vertebrate host, the highest levels of transcription may be by the L3s (Table 2). Interestingly, gerbils immunized with $B m$-SXP-1 showed substantial reduction (up to 97\%) in microfilarial numbers, as well as a partial reduction (approximately 35\%) in adult numbers following L3 challenge (100). Although the lower adult worm burden did not reach statistical significance, this outcome suggests that $B m-\mathrm{SXP}-1$ may be a suitable target for immunoprophylaxis against multiple stages of the filarial parasite.

\section{CYTOKINE AND CYTOKINE RECEPTOR-LIKE PROTEINS}

Three gene families have been discovered in filarial nematodes with similarities to mammalian cytokines, two of which (MIF and TGF- $\beta$ ) are likely to be of major importance in the host-parasite relationship, while the third [tumour protein homologue (TPH) or translationally controlled tumour protein (TCTP)] is of less certain significance. In the case of both MIF and TGF- $\beta$ families, two homologues from $B$. malayi have been isolated. However, the same gene families are represented in C. elegans (although with different expression patterns), and the question is being addressed of whether the filarial homologues fulfil physiological roles for the nematode or immunological roles for the parasitic mode of life.

\section{MIF: $B m-M I F-1$ and -2}

The macrophage migration inhibitory factor (MIF) gene family, derived from an ancient metazoan ancestor, encodes small (approximately 115-amino acid) proteins with many surprising features (101). For example, these proteins are secreted despite lacking a signal sequence, activate target cells through no known receptor, and display an unusual enzymatic activity dependent upon a proline at residue 2. Within the mammalian immune system, MIF has generally been considered a proinflammatory cytokine, but very recent work indicates that, dependent upon dose, MIF can equally exert a counter-inflammatory effect (102).

The EST database for B. malayi contains two distinct MIF homologues which encode proteins secreted by parasite $(7,14,18)$. At the amino acid level, Bm-MIF-1 is $40 \%$ identical to human MIF and only $27 \%$ identical to $B m$-MIF-2; the latter shares $28 \%$ of residues with the human homologue. Despite these differences, the three molecules show very similar cytokine-like activity (e.g. macrophage kinesis, monocyte activation and induction of endogenous cytokine secretion) as well as the enzyme activity (dopachrome tautomerase). We have also determined the crystal structure of Bm-MIF-2, which despite being only $28 \%$ identical to human MIF, presents a highly similar trimeric three-dimensional structure (14). The active site combines residues from adjacent monomers, so that trimerization is essential for biological function.

The function of parasite-derived MIF molecules is indeed a controversial question. In most in-vitro assays, $B m$-MIFs replicate the activity of human MIF, presenting a conundrum: why should a filarial parasite, intent on avoiding an inflammatory tissue reaction, secrete MIF homologues which are thought to amplify the inflammatory pathway? Currently, we favour the hypothesis that continuous secretion of MIF molecules by parasites may induce a counter-inflammatory phenotype, either by densensitization or by exposing host macrophages to a dose or duration of MIF not reproduced in vitro. Such a hypothesis may also explain the generation of 'alternatively activated macrophages' in filarial infections, which exert counter-inflammatory effects such as suppression of lymphocyte proliferation $(9,103,104)$. Recent results in mice repeatedly exposed to recombinant $\mathrm{Bm}$-MIF do indeed indicate that macrophages are induced to differentiate into a novel phenotype by the parasite molecule (Falcone et al., unpublished). If so, then the Bm-MIFs represent gene products which modulate the host immune system by recruiting and driving host cells into a more 'suppressive' mode. 


\section{TGF- $\beta$ family members (Bm-TGH-1 and -2)}

The transforming growth factor- $\beta$ superfamily includes a diverse set of intercellular signalling molecules controlling embryonic patterning and tissue differentiation, as well as regulation of immune responses. The morphogens are represented by Drosophila decapentaplegic (DPP) and mammalian bone morphogenetic proteins (BMPs), while the cytokine-like TGF- $\beta$ s constitute a distinct subfamily with an additional conserved cysteine in the mature protein (105). In the mid-1990s, it was established that TGF- $\beta$ family members were involved in $C$. elegans development (106). This prompted us to predict that Brugia would express similar proteins, and to hypothesize that at least one form in the parasitic nematode would be secreted to downregulate host immune cell responses.

Searching first by degenerate polymerase chain reaction, and then from Brugia EST sequences as they became available, two distinct TGF- $\beta$ homologues have been characterized. Almost identical tgh-1 genes were isolated from B. malayi and B. pahangi, which fall into the DPP/ BMP subfamily by sequence similarity. The 428 -amino acid protein contains a $C$-terminal homology domain corresponding to the mature 102-amino acid active product. This domain shows $62 \%$ amino acid identity to C. elegans DBL-1, $54 \%$ to DPP and $45 \%$ to mouse Nodal, a differentiation-inducing protein. Transcription is relatively low but peaks at periods surrounding growth in the mammalian host. However, expression is absent from the arrested microfilarial stage (13). This expression pattern, and the sequence analysis, suggested that $\mathrm{Bm}$-TGH-1 plays a role in the maturational physiology and growth of the filarial nematode.

A second TGF- $\beta$ homologue, designated TGH-2, has since been isolated from the EST dataset (8). The active domain contains an additional cysteine, as found in mammalian TGF$\beta$ s as well as other members of this subfamily (which include myostatin, a muscle-inducer in vertebrates as well as the $C$. elegans dauer-controlling product DAF-7). Bm-TGH-2 has properties which are more likely to represent a parasite immunomodulator: it is expressed by all stages resident in the mammal, especially by the microfilariae. Becuase this stage is devoid of developmental activity, such a pattern is inconsistent with a morphogen. Moreover, it is secreted by cultured adult and microfilariae of $B$. malayi, suggesting a role in the interaction with the host (8). Preliminary assays show a low but consistent level of binding to host TGF- $\beta$ receptors.

TGF- $\beta$ acts on cells through a heterodimeric receptor. In vertebrates and insects, a type II receptor chain ligates TGF- $\beta$, and phosphorylates the type I receptor, leading to a signal transduction cascade. The two receptors are related but quite distinct in their phosphorylation sites, and because the type I receptor may signal independently in some instances, it is throught to be the ancestral gene. The Brugia type I receptor has been cloned by PCR (107) but, despite repeated efforts, no type II receptor has been identified. A type II receptor, with recognizable homology to mammalian type II receptors, exists in C. elegans (DAF-4). Thus, the question remains open as to whether Brugia uses classical TGF- $\beta$ signalling pathways or has reverted to a simplified, one-subunit receptor system.

\section{Bm-TPH-1 (tumour protein homologue/histamine releasing factor)}

One of the abundant transcripts found in infective larvae is homologous to a proposed mammalian cytokine, histamine releasing factor (15). However, the identical sequence has been recorded as TCTP. In Brugia, this gene is transcribed throughout the life cycle (38). It is also secreted by the adult parasite, indicating that it may be available to play a role in the host-parasite interaction. Experiments to ascertain whether $\mathrm{Bm}$-TPH-1 can stimulate histamine release from human mast cells have so far given negative results (Falcone, personal communication).

\section{A BROADER IMMUNOLOGICAL PROFILE OF FILARIAE}

\section{The full genetic complement?}

The approximately 22000 ESTs from B. malayi represent about 8800 different genes. Of these, approximately 55\% have no significant similarity (a BLASTX score probability greater than e-10) to either $C$. elegans proteins, other known nematode proteins, or to any other sequences from other organisms represented in GenBank. This dataset is sufficiently extensive that comment can be passed on those gene families which are conspicuous by their absence. For example, catalase is not represented in $B$. malayi, although a catalase-like activity has been shown to protect adult and $\mathrm{mf}$ from hydrogen peroxideinduced damage (57). Interestingly, this enzyme is encoded in $O$. volvulus by the endosymbiotic Wolbachia (108). A similar contrast is with infective larvae of Toxocara canis, in which $6 \%$ of cDNAs encode a secreted C-type lectin (109), and yet not one member of this major gene family appears in the 20000 -strong $B$. malayi EST dataset.

(C) 2001 Blackwell Science Ltd, Parasite Immunology, 23, 327-344 


\section{Wolbachia antigens and lipopolysaccharides (LPS)}

The filarial nematodes harbour an intracellular rickettsialike bacterium related to the Wolbachia reproductive parasites of arthropods. The Wolbachia endosymbionts from B. malayi and $O$. volvulus have been selected for genome sequencing, and whole-genome clone maps have been built for $B$. malayi. The genomes are approximately $1 \mathrm{Mb}$ in size, and are likely to encode $2-3000$ protein products. While many may be involved in the bacterium-nematode interaction, some rickettsial proteins could exert effects at the nematode-mammal interface. Such products would be excellent candidates for new drug targets. Tetracycline has a significant effect on both $B$. malayi and $L$. sigmodontis in animal infections, resulting in reduced nematode survival and abrogation of fertility, while doxycycline has been trialled in human onchocerciasis with significant effect (110). Importantly, antibiotics known not to affect rickettsiae have no effect on worm survival, and nematode species that do not harbour bacteria are not affected by antibiotic treatment. The early IL-1 response of immune cells to crude antigens prepared from $B$. pahang has the hallmarks of an antilipopolysaccharide response, and can be abrogated by pretreatment with polymixinB, an anti-LPS agent. LPS is a cell wall product unique to bacteria, and thus the bacterial genome may be driving some of the response to the nematode (19,111-114).

\section{Non-peptide antigens}

Attention has increasingly focused on protein molecules because of the wealth of sequence information and the technical ease of expression and analysis of peptide products. However, it would be a mistake to ignore nonpeptide antigens. An important nonprotein component expressed by filarial nematodes is phosphorylcholine (115117), which is secreted by adult filariae (116) and forms the basis for the first circulating antigen test for bancroftian filariasis.

Phosphorylcholine may play a significant immunomodulatory role. First reports that phosphorylcholine-conjugates from B. malayi cause reduced $\mathrm{T}$ cell proliferation (118), have been followed by detailed studies on ES-62, a secreted phosphorylcholine-containing antigen from $A$. viteae which downregulates signalling in both $\mathrm{T}$ cells (119) and B cells (120) and induces dendritic cells towards a type 2 phenotype (121). ES-62 contains phosphorylcholine linked through a novel $N$-linked glycan $(122,123)$, while in $B$. malayi phosphorylcholine is O-linked (116).
Other protein modifications, especially glycosylation, are likely to have a major bearing on the immunological response to filarial antigens. For example, certain strains of mice are unable to recognize Bm-NPA-1 (gp15/400) or $B m$-GPX-1 (gp29) in their native, glycosylated state (124); however, immunization with nonglycosylated bacterially expressed forms of these antigens restores responsiveness to 'nonresponder' strains $(30,125)$. Although glycosylation per se was not shown to be responsible for these observations, this work illustrated that post-translational modifications of products may profoundly influence the immune response to individual filarial antigens.

\section{CONCLUSIONS}

Parasite immunology has been transformed by the molecular insights and precise tools offered from genome-led research. The filarial genes we discuss here include some of the most important players in successful parasite establishment in the immunocompetent host, but there are likely to be many more products to be discovered. Although the first generation of these filarial proteins is dominated by homologues of known gene families, for which gene function can quickly be deduced, there is bound to be an increasing emphasis on genes of unknown function, such as the filarial alts, particularly where they have diverged greatly from sequences in the free-living comparator, C. elegans. A further dimension which now needs to be assessed is how variable are different populations and strains of the filarial parasites, a question which can be asked with precision at the level of individual defined genes.

The new filarial molecular biology is likely to have a sweeping impact on research into and management of filarial disease. For example, the SPN-2 and SXP-1 proteins may provide excellent serodiagnostic tools, and additional recombinant antigens are now available to probe the pathways by which the immune response causes chronic disease in infection. For each functional protein which is characterized, a potential new drug target emerges, and with the application of structural biology to filarial proteins $(14,126)$, the design of new drugs on a rational basis will become possible. Several of the new proteins discussed here have been suggested as candidate vaccines for filariasis. Perhaps the prospects for the ALT antigens are most promising, as their larval-specific expression is unlikely to mean that immunized patients will develop exacerbated pathogenic responses to adult worms. In addition, the ALT proteins have the advantage of being filarialspecific, reducing the risk of damaging cross-reactivity 
to host or environmental antigens (127). Filariasis immunology is thus well-poised to integrate genomeled data into innovative research into one of the world's foremost parasitic diseases.

\section{REFERENCES}

1 Piessens WF, Partono F. Host-vector-parasite relationships in human filariasis. Semin Infect Dis 1980; 3: 131-152.

2 Eberhard ML. Longevity of microfilariae following removal of the adult worms. Trop Med Parasitol 1986; 37: 361-363.

3 Maizels RM, Bundy DAP, Selkirk ME, Smith DF, Anderson RM. Immunological modulation and evasion by helminth parasites in human populations. Nature 1993; 365: 797-805.

4 The Filarial Genome Project. Deep within the filarial genome: an update on progress in the Filarial Genome Project. Parasitol Today 1999; 15: 219-224.

5 Alcami A, Koszinowski UH. Viral mechanisms of immune evasion. Immunol Today 2000; 21: 447-455.

6 Tortorella D, Gewurz BE, Furman MH, Schust DJ, Ploegh HL. Viral subversion of the immune system. Annu Rev Immunol 2000; 18: 861-926.

7 Pastrana DV, Raghavan N, FitzGerald P et al. Filarial nematode parasites secrete a homologue of the human cytokine macrophage migration inhibitory factor. Infect Immun 1998; 66: 5955-5963.

8 Gomez-Escobar N, Gregory WF, Maizels RM. Identification of Bm-tgh-2, a filarial nematode homolog of C.elegans daf7 and human TGF- $\beta$, expressed in microfilarial and adult stages of Brugia malayi. Infect Immun 2000; 68: 64026410.

9 Loke P, MacDonald AS, Robb A, Maizels RM, Allen JE. Alternatively activated macrophages induced by nematode infection inhibit proliferation via cell to cell contact. Eur $J$ Immunol 2000; 30: 2669-2678.

10 Maizels RM, Lawrence RA. Immunological tolerance: the key feature in human filariasis? Parasitol Today 1991; 7: 271-276.

11 King CL, Kumaraswami V, Poindexter RW et al. Immunologic tolerance in lymphatic filariasis. Diminished parasite-specific $\mathrm{T}$ and $\mathrm{B}$ cell lymphocyte precursor frequency in the microfilaremic state. J Clin Invest 1992; 89: $1403-1410$.

12 Cookson E, Blaxter ML, Selkirk ME. Identification of the major soluble cuticular protein of lymphatic filarial nematode parasites (gp29) as a secretory homolog of glutathione peroxidase. Proc Natl Acad Sci USA 1992; 89: 5837-5841.

13 Gomez-Escobar N, Lewis E, Maizels RM. A novel member of the transforming growth factor- $\beta$ (TGF- $\beta$ ) superfamily from the filarial nematodes Brugia malayi and $B$ pahangi. Exp Parasitol 1998; 88: 200-209.

14 Zang XX, Taylor P, Meyer D et al. Functional homologs of human macrophage migration inhibitory factor (MIF) from the parasitic nematode Brugia malayi: conservation of activity and crystal structure. 2001; submitted.

15 Gregory WF, Blaxter ML, Maizels RM. Differentially expressed, abundant trans-spliced cDNAs from larval Brugia malayi. Mol Biochem Parasitol 1997; 87: 85-95.

16 Gregory WF, Atmadja AK, Allen JE, Maizels RM. The abundant larval transcript $1 / 2$ genes of Brugia malayi encode stage- specific candidate vaccine antigens for filariasis. Infect Immun 2000; 68: 4174-4179.

17 The C. elegans Genome Consortium. Genome sequence of Caenorhabditis elegans: a platform for investigating biology. Science 1998; 282: 2012-2018.

18 Blaxter ML, Raghavan N, Ghosh I et al. Genes expressed in Brugia malayi infective third stage larvae. Mol Biochem Parasitol 1996; 77: 77-93.

19 Williams SA, Lizotte-Waniewski MR, Foster J et al. The filarial genome project: analysis of the nuclear, mitochondrial and endosymbiont genomes of Brugia malayi. Int J Parasitol 2000; 30: 411-419.

20 Cookson E, Tang L, Selkirk ME. Conservation of primary sequence of gp29, the major soluble cuticular glycoprotein, in three species of lymphatic filariae. Mol Biochem Parasitol 1993; 58: $155-160$.

21 Blaxter ML. Caenorhabditis elegans is a nematode. Science 1998; 282: 2041-2046.

22 Maizels RM, Gregory WF, Kwan-Lim G-E, Selkirk ME. Filarial surface antigens: the major 29 kilodalton glycoprotein and a novel 17-200 kilodalton complex from adult Brugia malayi parasites. Mol Biochem Parasitol 1989; 32: 213-227.

23 Tang L, Gounaris K, Griffiths C, Selkirk ME. Heterologous expression and enzymatic properties of a seleniumindependent glutathione peroxidase from the parasitic nematode Brugia pahangi. $J$ Biol Chem 1995; 270: 18313-18318.

24 Tang L, Smith VP, Gounaris K, Selkirk ME. Brugia pahangi: the cuticular glutathione peroxidase (gp29) protects heterologous membranes from lipid peroxidation. Exp Parasitol 1996; 82: 329-332.

25 Devaney E. The biochemical and immunochemical characterisation of the 30 kilodalton surface antigen of Brugia pahangi. Mol Biochem Parasitol 1988; 27: 183-192.

26 Zvelebil MJJM, Tang L, Cookson E, Selkirk ME, Thornton JM. Molecular modelling and epitope prediction of gp29 from lymphatic filariae. Mol Biochem Parasitol 1993; 58: $145-154$.

27 Selkirk ME, Gregory WF, Jenkins RE, Maizels RM. Localization, turnover and conservation of gp15/400 in different stages of Brugia malayi. Parasitology 1993; 107: 449-457.

28 Tweedie S, Paxton WA, Ingram L, Maizels RM, McReynolds LA, Selkirk ME. Brugia pahangi and Brugia malayi: a surfaceassociated glycoprotein (gp15/400) is composed of multiple tandemly repeated units and processed from a 400-kDa precursor. Exp Parasitol 1993; 76: 156-164.

29 Kumari S, Lillibridge CD, Bakeer M, Lowrie RC Jr, Jayaraman K, Philipp MT. Brugia malayi: the diagnostic potential of recombinant excretory/secretory antigens. Exp Parasitol 1994; 79: 489-505.

30 Allen JE, Lawrence RA, Maizels RM. Fine specificity of the genetically controlled immune response to native and recombinant gp15/400 (polyprotein allergen) of Brugia malayi. Infect Immun 1995; 63: 2892-2898.

31 Kennedy MW. The nematode polyprotein allergens/antigens. Parasitol Today 2000; 16: 373-380.

32 Poole CB, Hornstra LJ, Benner JS, Fink JR, McReynolds LA. Carboxy-terminal sequence divergence and processing of the polyprotein antigen from Dirofilaria immitis. Mol Biochem Parasitol 1996; 82: 51-65. 
33 Paxton WA, Yazdanbakhsh M, Kurniawan A, Partono F, Maizels RM, Selkirk ME. Primary structure of and immunoglobulin E response to the repeat subunit of gp15/400 from human lymphatic filarial parasites. Infect Immun 1993; 61: 2827-2833.

34 Kennedy MW, Allen JE, Wright AS, McCruden AB, Cooper A. The gp15/400 polyprotein antigen of Brugia malayi binds fatty acids and retinoids. Mol Biochem Parasitol 1995; 71: 4150 .

35 Owhashi M, Futaki S, Kitagawa $\mathrm{K}$ et al. Molecular cloning and characterization of a novel neutrophil chemotactic factor from a filarial parasite. Mol Immunol 1993; 30: $1315-1320$.

36 Maizels RM, Partono F, Oemijati S, Denham DA, Ogilvie BM. Cross-reactive surface antigens on three stages of Brugia malayi. B. pahangi and B timori. Parasitology 1983; 87: 249263.

37 Maizels RM, Denham DA, Sutanto I. Secreted and circulating antigens of the filarial parasite Brugia pahangi: Analysis of vitro released components and detection of parasite products in vivo. Mol Biochem Parasitol 1985; 17: 277-278.

38 Gregory WF, Murray J, Abrahamson M, Maizels RM. Two cystatin-type cysteine protease inhibitors from the human filarial nematode Brugia malayi show differential developmental expression, distinct inhibition profiles, and differ in the presence or absence of a highly conserved glycine residue. 2001; submitted.

39 Bradley JE, Helm R, Lahaise M, Maizels RM. cDNA clones of Onchocerca volvulus low molecular weight antigens provide immunologically specific diagnostic probes. Mol Biochem Parasitol 1991; 46: 219-228.

40 Lustigman S, Brotman B, Huima T, Prince AM, McKerrow JH. Molecular cloning and characterization of Onchocystatin, a cysteine proteinase inhibitor of Onchocerca volvulus. J Biol Chem 1992; 267: 17339-17346.

41 Hartmann S, Kyewski B, Sonnenburg B, Lucius R. A filarial cysteine protease inhibitor down-regulates $\mathrm{T}$ cell proliferation and enhances interleukin-10 production. Eur J Immunol 1997; 27: 2253-2260.

42 Alvarez-Fernandez M, Barrett AJ, Gerhartz B, Dando PM, Ni J, Abrahamson M. Inhibition of mammalian legumain by some cystatins is due to a novel second reactive site. J Biol Chem 1999; 274: 19195-19203.

43 Manoury B, Hewitt EW, Morrice N, Dando PM, Barrett AJ, Watts C. An asparaginyl endopeptidase processes a microbial antigen for class II MHC presentation. Nature 1998; 396: 695699.

44 Manoury B, Gregory WF, Maizels RM, Watts C. CPI-2, a cystatin homolog secreted by the filarial parasite Brugia malayi, inhibits class II MHC-restricted antigen processing. Curr Biol 2001; 11: 447-451.

45 Bradley JE, Gregory WF, Bianco AE, Maizels RM. Biochemical and immunochemical characterisation of a 20-kilodalton complex of surface-associated antigens from adult Onchocerca gutturosa filarial nematodes. Mol Biochem Parasitol 1989; 34: 197-208.

46 Nirmalan N, Cordeiro NJV, Kläger SL, Bradley JE, Allen JE. Comparative analysis of glycosylated and nonglycosylated filarial homologues of the 20-kilodalton retinol binding protein from Onchocerca volvulus (Ov20). Infect Immun 1999; 67: 6329-6334.

47 Bradley JE, Tuan RS, Shepley KJ et al. Onchocerca volvulus:
Characterization of an immunodominant hypodermal antigen present in adult and larval parasites. Exp Parasitol 1993; 77: 414-424.

48 Kennedy MW, Garside LH, Goodrick LE et al. The Ov20 protein of the parasitic nematode Onchocerca volvulus. A structurally novel class of small helix-rich retinol-binding proteins. $J$ Biol Chem 1997; 272: 29442-29448.

49 Frank GR, Wisnewski N, Brandt KS, Carter CRD, Jennings NS, Selkirk ME. Molecular cloning of the 22-24 kDa excretory-secretory $22 \mathrm{U}$ protein of Dirofilaria immitis and other filarial nematode parasites. Mol Biochem Parasitol 1999; 98: $297-302$.

50 Allen JE, Daub J, Guilliano D et al. Analysis of genes expressed at the infective larval stage validate the utility of Litomosoides sigmodontis as a murine model for filarial vaccine development. Infect Immun 2000; 68: 5454-5458.

51 Dissanayake S, Xu M, Nkenfou C, Piessens WF. Molecular cloning and serological characterization of a Brugia malayi pepsin inhibitor homolog. Mol Biochem Parasitol 1993; 62: 143146 .

52 Lucius R, Schulz-Key H, Büttner DW et al. Characterization of an immunodominant Onchocerca volvulus antigen with patient sera and a monoclonal antibody. J Exp Med 1988; 167: 15051510 .

53 Tume C, Ngu JL, McKerrow JL et al. Characterization of a recombinant Onchocerca volvulus antigen (Ov33) produced in yeast. Am J Trop Med Hygiene 1997; 57: 626633

54 Bennett K, Levine T, Ellis JS et al. Antigen processing for presentation by class II major histocompatibility complex requires cleavage by cathepsin E. Eur J Immunol 1992; 22: $1519-1524$.

55 Tang L, Ou X, Henkle-Dührsen J, Selkirk ME. Extracellular and cytoplasmic $\mathrm{CuZn}$ superoxide dismutases from Brugia lymphatic filarial nematode parasites. Infect Immun 1994; 62: 961-967.

56 Ou X, Tang L, McCrossan M, Henkle-Dührsen K, Selkirk ME. Brugia malayi: localisation and differential expression of extracellular and cytoplasmic $\mathrm{CuZn}$ superoxide dismutases in adults and microfilariae. Exp Parasitol 1995; 80: 515529

57 Ou X, Thomas R, Chacón MR, Tang L, Selkirk ME. Brugia malayi: differential susceptibility to and metabolism of hydrogen peroxide in adults and microfilariae. Exp Parasitol 1995; 80: 530-540.

$58 \mathrm{Kim} \mathrm{K}$, Kim IH, Lee KY, Rhee SG, Stadtman ER. The isolation and purification of a specific 'protector' protein which inhibits enzyme inactivation by a thiol. Fe (III) $\mathrm{O} 2$ mixed-function oxidation system. J Biol Chem 1988; 263: 4704-4711.

59 Chae HZ, Robison K, Poole LB, Church G, Storz G, Rhee SG. Cloning and sequencing of thiol-specific antioxidant from mammalian brain: alkyl hydroperoxide reductase and thiol-specific antioxidant define a large family of antioxidant enzymes. Proc Natl Acad Sci USA 1994; 91: 7017-7021.

60 Ghosh I, Eisinger SW, Raghavan N, Scott AL. Thioredoxin peroxidases from Brugia malayi. Mol Biochem Parasitol 1998; 91: $207-220$.

61 Chandrashekar R, Curtis KC, Lu W, Weil G. Molecular cloning of an enzymatically active thioredoxin peroxidase from 
Onchocerca volvulus. Mol Biochem Parasitol 1998; 93: 309312.

$62 \mathrm{Lu} \mathrm{W}$, Egerton GL, Bianco AE, Williams SA. Thioredoxin peroxidase from Onchocerca volvulus: a major hydrogen peroxide detoxifying enzyme in filarial parasites. Mol Biochem Parasitol 1998; 91: 221-235.

63 Fuhrman JA, Urioste SS, Hamill BAS, Piessens WF.Functional and antigenic maturation of Brugia malayi microfilariae. Am J Trop Med Hygiene 1987; 36: 70-74.

64 Fuhrman JA, Lane WS, Smith RF, Piessens WF, Perler FB. Transmission-blocking antibodies recognize microfilarial chitinase in brugian lymphatic filariasis. Proc Natl Acad Sci USA 1992; 89: 1548-1552.

65 Fuhrman JA, Lee J, Dalamagas D. Structure and function of a family of chitinase isozymes from Brugian microfilariae. Exp Parasitol 1995; 80: 672-680.

66 Arnold K, Venegas A, Houseweart C, Fuhrman JA. Discrete transcripts encode multiple chitinase isoforms in Brugian microfilariae. Mol Biochem Parasitol 1996; 80: 149-158.

67 Blaxter M. Protein motifs in filarial chitinases. Parasitol Today 1996; 12: 42.

68 Tellam RL. Protein motifs in filarial chitinases: an alternative view. Parasitol Today 1996; 12: 291-292.

69 Venegas A, Goldstein JC, Beauregard K, Oles A, Abdulhayoglu $\mathrm{N}$, Fuhrman JA. Expression of recombinant microfilarial chitinase and analysis of domain function. Mol Biochem Parasitol 1996; 78: 149-159.

70 Fuhrman JA. Filarial chitinases. Parasitol Today 1995; 11: 259_ 261.

71 Adam R, Kaltmann B, Rudin W, Friedrich T, Marti T, Lucius R. Identification of chitinase as the immunodominant filarial antigen recognized by sera of vaccinated rodents. J Biol Chem 1996; 271: 1441-1447.

$72 \mathrm{Wu}$ Y, Adam R, Williams SA, Bianco AE. Chitinase genes expressed by infective larvae of the filarial nematodes, Acanthocheilonema viteae and Onchocerca volvulus. Mol Biochem Parasitol 1996; 75: 207-219.

73 Freedman DO, Nutman TB, Ottesen EA. Protective immunity in Bancroftian filariasis. Selective recognition of a $43-\mathrm{kD}$ larval stage antigen by infection-free individuals in an endemic area. J Clin Invest 1989; 83: 14-22.

74 Raghavan N, Freedman N, Freedman DO, Fitzgerald PC, Ottesen EA, Nutman TB. Cloning and characterization of a potentially protective chitinase-like recombinant antigen from Wuchereria bancrofti. Infect Immun 1994; 62: 19011908.

75 Selkirk ME, Yazdanbakhsh M, Freedman D, et al. A prolinerich structural protein of the surface sheath of larval Brugia filarial nematode parasites. J Biol Chem 1991; 266: 1100211008.

76 Zahner H, Hobom G, Stirm S. The microfilarial sheath and its proteins. Parasitol Today 1995; 11: 116-120.

77 Conraths FJ, Hirzmann J, Hebom G, Zahner H. Expression of the microfilarial sheath protein 2 (shp2) of the filarial parasites Litomosoides sigmodontis and Brugia malayi. Exp Parasitol 1997; 85: 241-248.

78 Zang XX, Yazdanbakhsh M, Kiang H, Kanost MR, Maizels RM. A novel serpin expressed by the blood-borne microfilariae of the parasitic nematode Brugia malayi inhibits human neutrophil serine proteinases. Blood 1999; 94: 14181428.
79 Zang XX, Atmadja AK, Gray $\mathrm{P}$ et al. The serpin secreted by Brugia malayi microfilariae, Bm-SPN-2, elicits strong, but shortlived, immune responses in mice and humans. J Immunol 2000; 165: 5161-5169.

80 Lawrence RA, Allen JE, Osborne J, Maizels RM. Adult and microfilarial stages of the filarial parasite Brugia malayi stimulate contrasting cytokine and immunoglobulin isotype responses in BALB/c mice. J Immunol 1994; 153: 12161224.

81 Yenbutr P, Scott AL. Molecular cloning of a serine proteinase inhibitor from Brugia malayi. Infect Immun 1995; 63: 17451753.

82 Zang X, Maizels RM. Serine proteinase inhibitors from nematodes and the arms race between host and pathogen. Trends Biochem Sciences 2001; 26: in press.

83 Maizels RM, Partono F, Oemijati S, Ogilvie BM. Antigenic analysis of Brugia timori, a filarial nematode of man: Initial characterisation by surface radio-iodination and evaluation of diagnostic potential. Clin Exp Immunol 1983b; 51: 269-277.

84 Blaxter M, Liu L. Nematode spliced leaders - ubiquity, evolution and utility. Int J Parasitol 1996; 26: 1025-1033.

85 Gems DH, Ferguson CJ, Robertson BD, Page AP, Blaxter ML, Maizels RM. An abundant, trans-spliced mRNA from Toxocara canis infective larvae encodes a $26 \mathrm{kDa}$ protein with homology to phosphatidylethanolamine binding proteins. J Biol Chem 1995; 270: 18517-18522.

86 Frank GR, Tripp CA, Grieve RB. Molecular cloning of a developmentally regulated protein isolated from excretorysecretory products of larval Dirofilaria immitis. Mol Biochem Parasitol 1995; 75: 231-240.

87 Joseph GT, Huima T, Lustigman S. Characterization of an Onchocerca volvulus L3-specific larval antigen, Ov-ALT-1. Mol Biochem Parasitol 1998; 96: 177-183.

88 Pogonka T, Oberlander U, Marti T, Lucius R. Acanthocheilonema viteae: characterization of a molt-associated excretory/secretory 18-kDa protein. Exp Parasitol 1999; 93: 7381.

89 Seeber F, Brattig N, Soboslay PT et al. Characterization of a recombinant $\mathrm{T}$ cell and $\mathrm{B}$ cell reactive polypeptide of Onchocerca volvulus. J Immunol 1993; 150: 2931-2944.

90 Hawdon JM, Jones BF, Hoffman DR, Hotez PJ. Cloning and characterization of Ancylostoma-secreted protein. A novel protein associated with the transition to parasitism by infective hookworm larvae. J Biol Chem 1996; 271: 66726678.

91 Moyle M, Foster DL, McGrath DE et al. A hookworm glycoprotein that inhibits neutrophil function is a ligand of the integrin CD11b/CD18. J Biol Chem 1994; 269: 1000810015.

92 Tawe W, Pearlman E, Unnasch TR, Lustigman S. Angiogenic activity of Onchocerca volvulus recombinant proteins similar to vespid venom antigen 5. Mol Biochem Parasitol 2000; 109: 9199.

93 Hawdon JM, Narasimhan S, Hotez PJ. Ancylostoma secreted protein 2: cloning and characterization of a second member of a family of nematode secreted proteins from Ancylostoma caninum. Mol Biochem Parasitol 1999; 99: $149-165$.

94 Daub J, Loukas A, Pritchard D, Blaxter ML. A survey of genes expressed in adults of the human hookworm Necator americanus. Parasitology 2000; 120: 171-184. 
95 Murray J, Gregory WF, Atmadja K, Gomez-Escobar N, Maizels RM. Expression and immune recognition of Brugia malayi VAL1, a homologue of vespid venom allergens and Ancylostoma secreted proteins. 2001; submitted.

96 Dissanayake S, Zheng H, Dreyer G et al. Evaluation of a recombinant parasite antigen for the diagnosis of lymphatic filariasis. Am J Trop Med Hygiene 1994; 50: 727-734.

97 Dissanayake S, Xu M, Piessens WF. A cloned antigen for serological diagnosis of Wuchereria bancrofti microfilaremia with daytime blood samples. Mol Biochem Parasitol 1992; 56: 269-278.

98 Rao KVN, Eswaran M, Ravi V et al. The Wuchereria bancrofti orthologue of Brugia malayi SXP1 and the diagnosis of bancroftian filariasis. Mol Biochem Parasitol 2000; 107: 7180.

99 Chandrashekar R, Curtis KC, Ramzy RM, Liftis F, Li B-W, Weil G. Molecular cloning of Brugia malayi antigens for diagnosis of lymphatic filariasis. Mol Biochem Parasitol 1994; 64: 261-271.

100 Wang SH, Zheng HJ, Dissanayake S et al. Evaluation of recombinant chitinase and SXP1 antigens as antimicrofilarial vaccines. Am J Trop Med Hygiene 1997; 56: 474-481.

101 Bucala R. A most interesting factor. Nature 2000; 408: 146147.

102 Kleemann $\mathrm{R}$ et al. Intracellular action of the cytokine MIF to modulate AP-1 activity and the cell cycle through Jab1. Nature 2000; 408: 211-216.

103 Allen JE, Lawrence RA, Maizels RM. Antigen presenting cells from mice harboring the filarial nematode, Brugia malayi, prevent cellular proliferaton but not cytokine production. Int Immunol 1996; 8: 143-151.

104 MacDonald AS, Maizels RM, Lawrence RA, Dransfield I, Allen JE. Requirement for in vivo production of IL-4, but not IL-10, in the induction of proliferative suppression by filarial parasites. J Immunol 1998; 160: 4124-4132.

105 Letterio JJ, Roberts AB. Regulation of immune responses by TGF- $\beta$. Аппи Rev Immunol 1998; 16: 137-161.

106 Ren P, Lim C-S, Johnsen RJ, Albert PS, Pilgrim D, Riddle DL. Control of C.elegans larval development by neuronal expression of a TGF- $\beta$ homolog. Science 1996; 274: 13891391.

107 Gomez-Escobar N, van den Biggelaar A, Maizels RM. A member of the TGF- $\beta$ receptor gene family in the parasitic nematode Brugia. Gene 1997; 199: 101-109.

108 Henkle-Dührsen K, Eckelt VO, Wildenburg G, Blaxter M, Walter RD. Gene structure, activity and localization of a catalase from intracellular bacteria in Onchocerca volvulus. Mol Biochem Parasitol 1998; 96: 69-81.

109 Tetteh KKA, Loukas A, Tripp C, Maizels RM. Identification of abundantly-expressed novel and conserved genes from infective stage larvae of Toxocara canis by an expressed sequence tag strategy. Infect Immun 1999; 67: 4771-4779.

110 Hoerauf A, Volkmann L, Hamelmann C et al. Endosymbiotic bacteria in worms as targets for a novel chemotherapy in filariasis. Lancet 2000; 355: 1242-1243.

111 Bandi C, Anderson TJC, Genchi C, Blaxter ML. Phylogeny of Wolbachia-like bacteria in filarial nematodes. Proc R Soc London Series B 1998; 265: 2407-2413.

112 Hoerauf A, Nissen-Pähle K, Schmetz C et al. Tetracycline therapy targets intracellular bacteria in the filarial nematode
Litomosoides sigmodontis and results in filarial infertility. J Clin Invest 1999; 103: 11-18.

113 Brattig NW, Rathjens U, Ernst M, Geisinger F, Renz A, Tischendorf FW. Lipopolysaccharide-like molecules derived from Wolbachia endobacteria of the filaria Onchocerca volvulus are candidate mediators in the sequence of inflammatory and anti-inflammatory responses of human monocytes. Microbes Infect 2000; 2: 1147-1157.

114 Taylor MJ, Cross HF, Bilo K. Inflammatory responses induced by the filarial nematode Brugia malayi are mediated by lipopolysaccharide-like activity from endosymbiotic Wolbachia bacteria. J Exp Med 2000; 191: 14291435.

115 Gualzata M, Weiss N, Heusser CH. Dipetalonema viteae: phosphorylcholine and non-phosphorylcholine antigen determinants in infective larvae and adult worms. Exp Parasitol 1986; 61: $95-102$.

116 Maizels RM, Burke J, Denham DA. Phosphorylcholinebearing antigens in filarial nematode parasites: analysis of somatic extracts and in vitro secretions of Brugia malayi and B. pahangi and infection sera. Parasite Immunol 1987; 9: 4966.

117 Wenger JD, Forsyth KP, Kazura JW. Identification of phosphorylcholine epitope-containing antigens in Brugia malayi and relation of serum epitope levels to infection status of jirds with Brugian filariasis. Am J Trop Med Hygiene 1988; 38: 133141.

118 Lal RB, Kumaraswami V, Steel C, Nutman TB. Phosphocholine-containing antigens of Brugia malayi nonspecifically supress lymphocyte function. Am J Trop Med Hygiene 1990; 42: 56-64.

119 Harnett MM, Deehan MR, Williams DM, Harnett W. Induction of signalling anergy via the $\mathrm{T}$-cell receptor in cultured Jurkat $\mathrm{T}$ cells by pre-exposure to a filarial nematode secreted product. Parasite Immunol 1998; 20: 551-563.

120 Deehan MR, Frame MJ, Parkhouse RME et al. A phosphorylcholine-containing filarial nematode-secreted product disrupts B lymphocyte activation by targeting key proliferative signaling pathways. J Immunol 1998; 160: 2692-2699.

121 Whelan M, Harnett MM, Houston KM, Patel V, Harnett W, Rigley KP. A filarial nematode-secreted product signals dendritic cells to acquire a phenotype that drives development of $\mathrm{Th} 2$ cells. J Immunol 2000; 164: 6453-6460.

122 Harnett W, Houston KM, Amess R, Worms MJ. Acanthocheilonema viteae: phosphorylcholine is attached to the major excretory-secretory product via an N-linked glycan. Exp Parasitol 1993; 77: 498-502.

123 Haslam SM, Khoo K-H, Houston KM, Harnett W, Morris HR, Dell A. Characterisation of the phosphorylcholine-containing Nlinked oligosaccharides in the excretory-secretory $62 \mathrm{kDa}$ glycoprotein of Acanthocheilonema viteae. Mol Biochem Parasitol 1997; 85: 53-66.

124 Kwan-Lim G-E, Maizels RM. MHC and non-MHC restricted recognition of filarial surface antigens in mice transplanted with adult Brugia malayi parasites. J Immunol 1990; 145: 19121920.

125 Chacón MR, Londoño P, Dougan G, Selkirk ME. Heterologous expression of the cuticular glutathione peroxidase of lymphatic filariae in an attenuated vaccine strain of Salmonella typhimurium 
abrogates $\mathrm{H}-2$ restriction of specific antibody responses. Parasite Immunol 1996; 18: 307-316.

126 Taylor P, Page AP, Kontopidis G, Husi H, Walkinshaw MD. The $\mathrm{X}$-ray structure of a divergent cyclophilin from the nematode parasite Brugia malayi. FEBS Lett 1998; 425: 361-366.
127 Maizels RM, Holland M, Falcone FH, Zang XX, Yazdanbakhsh M. Vaccination against helminth parasites: the ultimate challenge for immunologists? Immunol Rev 1999; 171: 125148. 